\title{
Plantas de papier-mâché. Estudios técnicos y conservación de la colección Brendel del Colegio Nacional de Buenos Aires. Argentina
}

\author{
María Gabriela Mayoni
}

Resumen: Durante la segunda mitad del siglo XIX en Europa fueron realizados en papel maché, modelos para la enseñanza de la anatomía humana, la zoología y la botánica con gran demanda en universidades y escuelas de diferentes partes del mundo. El Colegio Nacional de Buenos Aires, fundado en 1863, adquirió para sus gabinetes de ciencias modelos procedentes de Francia y Alemania que fueron recuperados, durante el periodo 2007-2012, a través de un proyecto integral de documentación, conservación y restauración. En este artículo se exponen los resultados del trabajo realizado sobre la colección alemana Brendel, integrada por modelos para la enseñanza de la botánica. Los estudios técnicos y de laboratorio, los documentos históricos y las referencias tomadas de otras colecciones, permitieron construir la base de información sobre las que se apoyaron los criterios y la toma de decisiones en relación a su conservación y restauración.

Palabras clave: papel maché, modelos botánicos, Brendel, estudios técnicos, conservación, restauración

\section{Papier-mâché plants. technical studies and conservation of the collection Brendel. Colegio Nacional de Buenos Aires. Argentina.}

\begin{abstract}
During the middle of the 19th century in Europe, models to teach human anatomy, zoology and botanic were made in papier mache and were demanded for universities and colleges all over the world. The Colegio Nacional de Buenos Aires funded in 1863, acquired models from France and Germany for their scientific cabinets, which were recovered some years ago through an integral project of documentation, conservation and restoration. In this paper, will be exposed the results on Brendel german collection, engaged in the production of models to teach botany. The technics studies, the historic documents and the references of other collections allowed us to build the information base on which the criteria are supported, and what were the process of decision making of regards its conservation and restoration.
\end{abstract}

Key words: papier mache, botanical models, Brendel, technics studies, conservation, restoration

\section{Modelos de Papier-mâché. Estudos técnicos e conservação da coleção Brendel do Colégio Nacional de Buenos Aires, Argentina.}

Resumo: Durante a segunda metade do século XX, fizeram-se na Europa modelos em papel mâche para utilizar no ensino da anatomia humana, da zoologia e da botânica. Estes modelos eram muito requisitados pelas universidades e escolas de todo o mundo. O Colégio Nacional de Buenos Aires, fundado em 1863, adquiriu para os seus departamentos de ciências modelos provenientes da França e da Alemanha que foram recuperados durante o período de 2007/2012 através de um projeto integral de documentação, conservação e restauração. Expor-se-ão aqui os resultados desse trabalho realizado sobre a coleção alemã Brendel dedicada ao fabrico de modelos para o ensino da área botânica. Os estudos técnicos e de laboratório, os documentos históricos e as referências de outras colecções, permitiram construir a base de dados na qual se apoiaram os critérios e as decisões em relação à sua conservação e restauração.

Palavras-chave: papel mâche, modelos botânicas, Brendel, estudos técnicos, conservação, restauração 


\section{Introducción}

En las últimas dos décadas se ha generado un creciente interés por el estudio y preservación de antiguas colecciones de enseñanza científica, conservadas en instituciones de diferentes partes del mundo. Esos objetos, algunos todavía en uso y otros ya descartados como auxiliares de la enseñanza, han adquirido una nueva funcionalidad como parte de un patrimonio histórico a preservar en estos establecimientos. Varias líneas de investigación se han abierto a partir de las tareas de documentación, conservación y restauración de materiales y aparatos científicos antiguos, existentes en centros de enseñanza secundaria y superior de distintas partes del mundo. Las colecciones didácticas para la enseñanza de las ciencias tales como los modelos anatómicos, las láminas, los animales taxidermizados, los herbarios, los aparatos e instrumentos científicos, entre otros, son considerados actualmente un corpus de interés para investigar múltiples aspectos de la cultura material y visual de la ciencia y la educación (cf. García y Mayoni 2013). Esto ha dado lugar a varias publicaciones y a la creación de repositorios y catálogos virtuales de diversas colecciones, que proveen recursos para realizar la identificación de piezas y estudios comparativos.

En este marco, el Colegio Nacional de Buenos Aires (CNBA) en Argentina, fue una de las instituciones que llevó adelante un Programa de Preservación y Revalorización de Bienes Culturales para la puesta en valor de sus colecciones históricas (cf. Mayoni et all. 2012). Este colegio de enseñanza media es uno de los más antiguos del país y sus antecedentes se remontan a la época colonial como colegio jesuita, siendo varias veces reestructurado durante el siglo XIX (cf. Sanguinetti 1963). En 1863, se reorganizó como un colegio nacional que ofrecía una enseñanza preparatoria para la universidad, constituyéndose en un modelo a seguir para la organización de otros colegios nacionales en el país. En la actualidad cuenta con numerosas colecciones dentro de sus gabinetes de ciencias, algunas de las cuales datan de mediados del siglo XIX. Asociado a estos elementos de enseñanza existe además diversa documentación, como antiguos inventarios y fichas de registro, catálogos de casas proveedoras y folletos explicativos para su uso, entre otros.

El Programa de Preservación llevado a cabo en el Colegio Nacional, apuntó en primera instancia, a la puesta en valor de diferentes colecciones históricas utilizadas para la enseñanza de las ciencias. Las principales tareas estuvieron enfocadas en la recopilación de la documentación existente asociada a las mismas, en el registro fotográfico y la clasificación de toda la información, y en la planificación para el estudio, conservación y restauración de los objetos en diferentes etapas. A los largo de los cinco años de duración de este Programa (2007-2012) se realizaron trabajos de preservación en colecciones de modelos anatómicos de plantas, animales y el cuerpo humano pertenecientes al Departamento de Biología y en la colección de globos terráqueos y mapas murales del Departamento de Geografía (González Gass 2010).También se realizó el soporte técnico de registro y conservación preventiva de toda la colección histórica de aparatos, instrumentos, libros y documentos del Departamento de Química que dio origen al Museo Histórico de la Enseñanza de la Química (MHEQ)'. Por otra parte, el llamado Grupo de Conservación ${ }^{2}$, a cargo del taller de preservación dentro de la institución, colaboró en la restauración de otros objetos como los modelos anatómicos pertenecientes al Museo Didáctico de Física del Colegio que ya contaba con un importante trabajo de registro y preservación de sus colecciones.

Los diferentes proyectos se idearon en torno a tres ejes: investigación, conservación, y transferencia y divulgación. Por un lado, el acercamiento con la comunidad educativa y su consenso sobre los trabajos de conservación fue un factor importante en el proceso de patrimonialización de las colecciones históricas. En esos años, se organizaron diversas actividades con los alumnos tales como un taller sobre taxonomía vegetal, tomando como referencia los ejemplares de la colección, charlas sobre los oficios y técnicas de los objetos y también un taller práctico de realización llamado "Taller de réplicas", donde los alumnos y docentes trabajaron sobre técnicas artesanales y técnicas pictóricas imitando las usadas en los modelos anatómicos del siglo XIX. La articulación entre la disciplina de la preservación y la educación propició nuevos diálogos y trabajos conjuntos en la institución, abriendo las puertas a un cambio en la concepción de sus colecciones antiguas y a la creación de nuevas estrategias didácticas a través de ellas (cf. Mayoni 2011). Por otro lado, la investigación y el análisis aplicado a la conservación y restauración se desarrollaron con mayor énfasis con algunas colecciones según las necesidades y prioridades para su preservación. En este sentido, los proyectos realizados sobre los modelos anatómicos del Departamento de Biología, fueron los que más han incorporado estos aspectos. La puesta en valor de los modelos botánicos en papel maché de la firma alemana Robert Brendel fue el primero de ellos (2007 y 2009).

Los modelos Brendel fueron fabricados entre 1860 y 1920 y representan diversos tipos botánicos -algas, bacterias, musgos, helechos y plantas superiores- en diferentes escalas. Estos modelos tuvieron una gran circulación y su presencia se registra en instituciones de educación superior, secundaria y museos de historia natural de todo el mundo. En los inicios de la investigación, entre los años 2007 y 2008 , se pudo acceder a algunas colecciones en otras instituciones que sirvieron como referencia: la del Museo de Farmacobotánica de la Universidad de Buenos Aires, la de la Universidad de Utrecht, y la de la Universidad Complutense de Madrid. Esas colecciones y los estudios publicados por investigadores de estas y otras instituciones, favorecieron el conocimiento sobre estos objetos. A pesar de ello, no se hallaron en ese momento, trabajos publicados con estudios sobre las técnicas y los materiales utilizados por la firma Brendel. Esta ausencia 

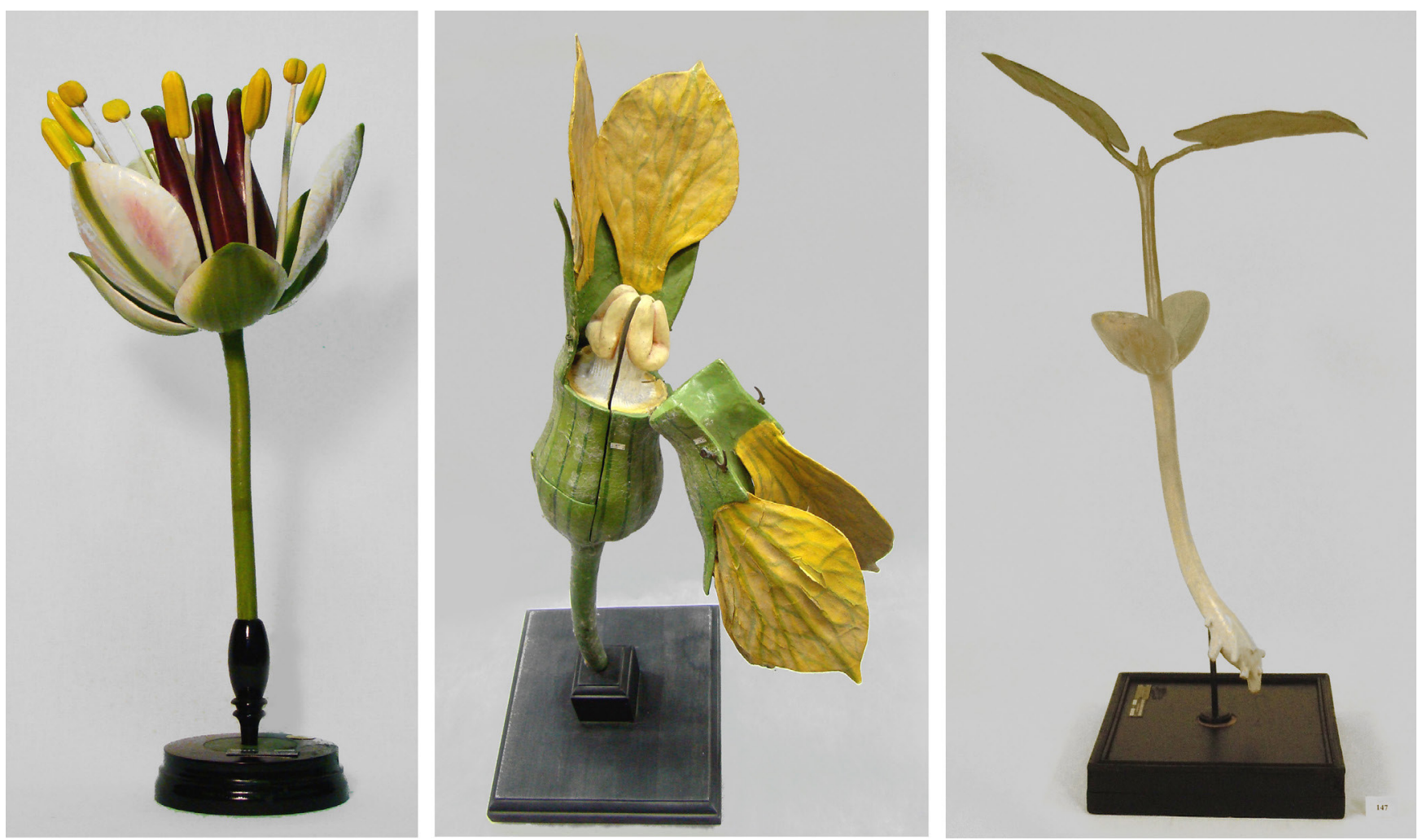

Figura 1.- Modelos botánicos de las firmas Brendel, Auzoux y Deyrolle respectivamente. Colección CNBA (Brendel y Deyrolle) e IES Isabel la Católica, España (Auzoux).

contrasta con la atención que si se ha prestado en los últimos años a los modelos en papel maché del doctor francés Louis Thomas Jèrôme Auzoux (1797-1880), considerado el primero en desarrollar la fabricación en serie de modelos anatómicos en papel maché para la enseñanza de la anatomía humana, la zoología y la botánica3 ${ }^{3}$. Cabe destacar que las técnicas utilizadas por Auzoux en sus modelos difieren de las utilizadas en los modelos Brendel, visibles en la presentación, construcción de las formas y el tratamiento de la superficie. Asimismo, los modelos botánicos Brendel se diferencian también de los modelos que fabricaba su contemporáneo francés Emile Deyrolle en escayola. [Figura 1].

Los modelos Brendel son complejos en su constitución ya que poseen una combinación de numerosos y diversos materiales. Si bien el papel y la técnica del papel maché es la mayormente utilizada, la firma también se valió de otros materiales y técnicas para la representación de los especímenes botánicos. En este sentido, la falta de estudios en profundidad impulsó la investigación analítica de las técnicas de fabricación en el marco del proyecto del CNBA. Dicha información resultaba relevante para la identificación de materiales y la posterior diferenciación de estos modelos. Además permitió la corroboración de las hipótesis preliminares sobre materiales y la comparación con la información encontrada en los trabajos publicados sobre Brendel ${ }^{4}$.

Actualmente, en el marco de una investigación doctoral sobre las colecciones utilizadas en la enseñanza de la historia natural en los colegios nacionales argentinos durante el periodo $1870-1920^{5}$, se ha podido avanzar en el conocimiento de estos objetos a través de nuevas fuentes de información. Estas incluyen documentos históricos locales, catálogos originales del fabricante y nuevos referentes en otras instituciones del mundo. Además, se ha observado una creciente exposición de los modelos Brendel en diferentes instituciones, producto de la creciente apertura de las mismas al público en general. Estos hechos invitan a avanzar en el análisis de las piezas y su posterior estudio comparativo. En este marco, el objetivo de este trabajo es presentar los resultados del proyecto sobre los modelos de esta firma, realizado en el Colegio Nacional de Buenos Aires. Este proyecto incluyó la profundización del conocimiento de las técnicas y materiales de fabricación y a su vez indagó a través de los objetos, sobre la historia y antecedentes de este tipo de material didáctico, de su tecnología en relación al uso del papel maché durante el siglo XIX, la historia de la empresa y las dinámicas de adquisición en el contexto local. En las siguientes páginas se analizan estos datos y a su vez se detallan los criterios y técnicas utilizadas en la instancia de restauración de la colección.

\section{La técnica del papel maché}

El papel maché es una técnica antigua procedente de la cultura oriental que permite la obtención de un material 
duro, resistente y de bajo costo. La base de la técnica es la utilización de la celulosa, que puede obtenerse de las fibras del algodón o de la madera. La misma puede realizarse por capas o con pasta de papel triturado, a la que se le agrega un aglutinante como adhesivo y diversos aditivos para la perdurabilidad y la resistencia a los cambios climáticos. Las propiedades físicas más importantes del producto obtenido con esta técnica, son la dureza y la resistencia a los golpes, la liviandad y la versatilidad. Manejando las variables "aglutinante", "adhesivo", "aditivos" y "acabado superficial" pueden lograrse materiales a base de celulosa con diversidad de propiedades fisicoquímicas.

Esta técnica y los productos obtenidos con la misma, fueron adaptados a diversos usos y necesidades como la construcción de mobiliario y accesorios decorativos, ornamentos y altos relieves en arquitectura, muebles y objetos decorativos, esculturas, muñecos y juguetes, máscaras y objetos etnográficos, modelos artísticos y didácticos, globos terráqueos, entre otras cosas (cf. van der Reyden y Williams 1986; Thornton 1993; García Adán 2014). Los estudios sobre el papel maché son diversos y están asociados a casos particulares y adaptaciones puntuales de la técnica. Si bien todos tratan el tema de la pasta de papel como sustrato, cada uno aporta nuevos datos técnicos y nueva información sobre sus posibilidades, contexto y tipo de objetos en que fue aplicado.

En el caso de los modelos tridimensionales para la enseñanza de las ciencias, varios trabajos reconocen que la utilización del papel maché fue empleado primero para la producción de ejemplares destinados al estudio de la anatomía humana en la década de 1820. Este uso se extendióluego a la construcción de ejemplares deanimales y plantas cuando se amplió la enseñanza agronómica y de la historia natural en la segunda parte del siglo XIX (cf. Cocks 2014). En este sentido, la utilización de la pasta de papel para modelar piezas anatómicas fue una alternativa al uso de la cera, la madera, el vidrio y el yeso, lográndose objetos resistentes a la manipulación diaria de docentes y alumnos, a los climas y a su transporte (Daston 2008; Orly 2000; Volkmar 1910:133). Mientras que la madera resultaba un material pesado, costoso y laborioso, la cera no resistía a las altas temperaturas y a una manipulación asidua, siendo endeble y quebradiza. Asimismo el vidrio fue un material con muchas limitaciones para su uso en las aulas. También el yeso, que en esa época fue otra alternativa accesible, podía resultar frágil a golpes y caídas.

La pasta de papel presentaba la ventaja de su bajo peso, el bajo costo y de poder ajustarse a la fabricación en serie. Al mismo tiempo, facilitó el armado de modelos de gran tamaño con piezas móviles y desarmables, que recibirían el nombre de modelos o cuerpos "clásticos". Este término, "clastique" en idioma francés, fue acuñado en las primeras décadas del siglo XIX, por el mencionado médico L. T. J. Auzoux, considerado el primero en adaptar la técnica del papel maché para la realización de ejemplares desarmables del cuerpo humano (Grob 2000). El uso del papel maché permitió explotar las posibilidades de diseño de estos "cuerpos clásticos" para que en el aula se pudieran seguir los procesos de una verdadera disección a través de la visualización de diferentes planos anatómicos y detalles de estructuras internas (cf. Cocks 2014; Degueurce 2012; Charles Ruiz 2010; Valdecasas et. al. 2009; García Fernández et. al 2009; Motel 2004; Grob 2000; Auzoux 1858). Los modelos de Auzoux se destacaron por la atención prestada a numerosos detalles anatómicos y el cuidado en mantener las proporciones en escala de las representaciones ${ }^{6}$. Estos modelos fueron adquiridos por instituciones de distintas partes del mundo y sirvieron como ejemplo para otras empresas en la segunda mitad del siglo XIX.

En la década de 1860 otros fabricantes se sumaron a la

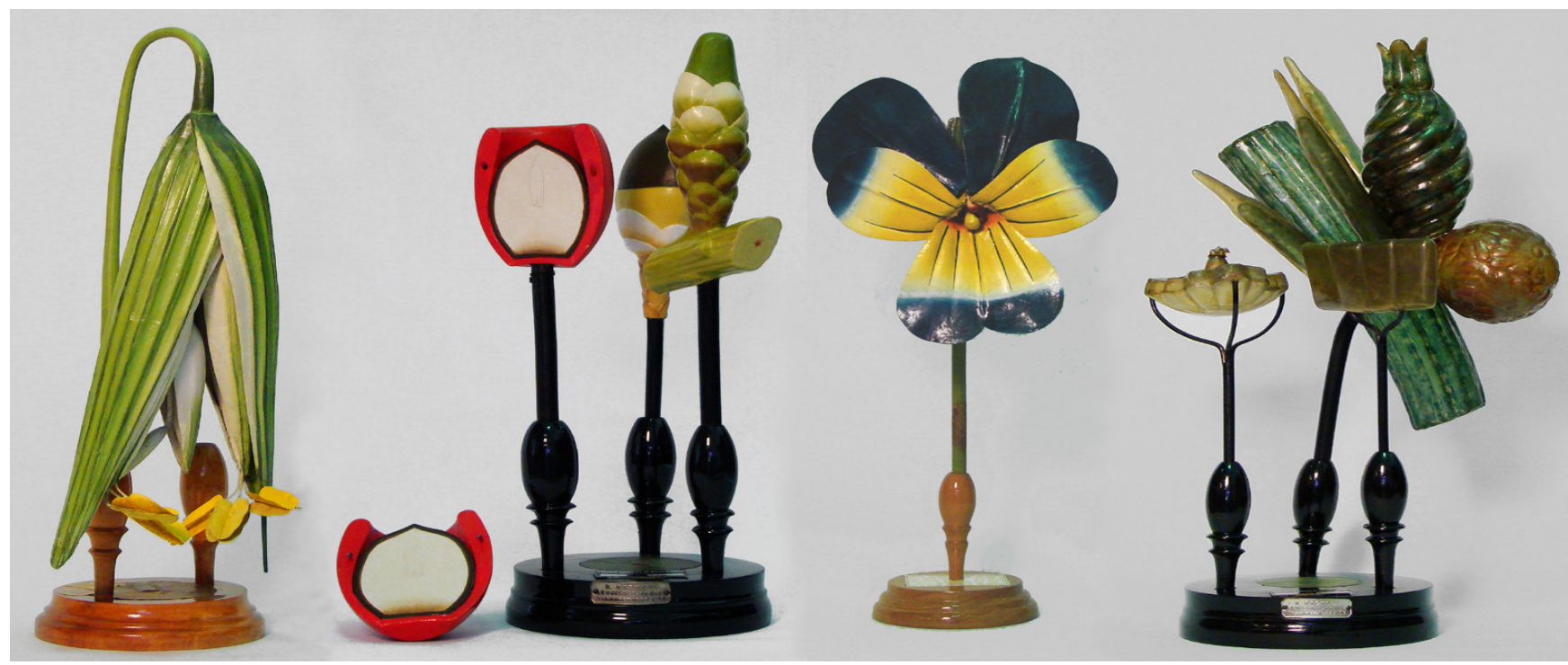

Figura 2.- Modelos botánicos R. Brendel. Colección Colegio Nacional de Buenos Aires (CNBA). 
producción en papel maché de ejemplares para acompañar los cursos de zoología y botánica. Entre ellos, se encontraba la firma alemana Brendel, dedicada a modelos botánicos como los que se conservan en el Colegio Nacional de Buenos Aires. Estos modelos fueron también muy comercializados y distribuidos a diferentes partes del mundo. Dentro del ámbito europeo, colecciones de este fabricante pueden encontrarse en el Museo de Historia Natural de Liverpool (200 ejemplares) ${ }^{7}$, la Facultad de Farmacia y Botánica de la Universidad Complutense de Madrid (196 ejemplares) ${ }^{8}$, la Universidad de Florencia (168 ejemplares) ${ }^{9}$ y la Universidad de Utrecht (140 ejemplares) ${ }^{10}$, entre otras instituciones. [Figura 2].

\section{Los modelos Brendel}

La producción de los modelos botánicos de la empresa Brendel tuvo lugar entre las décadas de 1860 y 1920. La firma fue fundada en 1866 por Robert Brendel (c. 18211898) en Breslau. Brendel asumió la producción industrial de los modelos ideados originalmente por el profesor Ferdinand Julius Cohn (1828-1898) y con indicaciones del farmacéutico Carl Leopold Lohmeyer (cf. Reiling 2009, 2003; Fiorini et. al. 2008; Seddon 1994; Brendel 1913-1914). Su comercialización se inició con 30 modelos de flores, llegando hacia 1914, a contar con más de 200 modelos de diversas especies para la enseñanza de la medicina, la agronomía y el estudio sistemático de la anatomía vegetal y con la colaboración de otros especialistas de la época (Forunier 1866, Brendel 1913-1914). A principios del siglo $\mathrm{XX}$, en los catálogos de venta de la firma, así como de otras empresas que comercializaban sus modelos, se ofrecían los modelos agrupados según el sistema de clasificación del botánico alemán Adolf Engler y en "series" según grupos botánicos o por su utilidad, como por ejemplo, algas, hongos y musgos, plantas frutales, plantas ornamentales, anatomías y diagramas esquemáticos, entre otros ${ }^{11}$. La información obtenida de los catálogos puede además resultar útil al compararlos, por ejemplo, con los programas de estudios de la época de cada institución y así reconocer la posible demanda para el desarrollo de las asignaturas.
Robert Brendel falleció en 1898 y el negocio quedó en manos de su hijo Reinhold (c. 1861-1927), quien ya habría promovido cambios en la empresa. La fábrica se encontraba en el oeste de Berlin para esa fecha y en 1902 fue llevada a Grünewald, en las afueras de la ciudad (Reiling 2009). Desde sus comienzos, la compañía recibió varias menciones y premios en exposiciones internacionales y sus modelos fueron ampliamente difundidos en gacetillas de sociedades científicas y promovidos por diferentes comerciantes. Lamentablemente no se cuenta con demasiada información del funcionamiento de la firma y sus movimientos. Como se menciona en los estudios de Reiling $(2000,2009)$ y Fiorini (2008), los registros y archivos de la empresa parecen haberse disipado durante el siglo XX luego de la muerte de Reinhold Brendel en 1927.

En este sentido, la información que se obtuvo de los objetos también fue aprovechada para poder discernir cambios o diferenciar períodos de producción de la empresa, como así también conocer la antigüedad aproximada de cada ejemplar al no contar con los registros exactos de adquisición e ingreso de colecciones en la institución. En el caso del CNBA, cada modelo Brendel posee una etiqueta impresa con información sobre el espécimen representado, indicando generalmente, su nombre científico, el nombre vernáculo en varios idiomas -alemán, inglés, francés e italiano-, y la familia botánica a la que pertenecía. La clasificación taxonómica del ejemplar puede también usarse para datar ya que los sistemas de clasificación fueron cambiando y es posible ubicar temporalmente el uso de determinados nombres. Las etiquetas pueden incluir además, otra información del modelo, como la escala utilizada en la representación, el número de orden del catálogo y la ciudad y dirección de emplazamiento de la empresa. En la colección del Colegio Nacional se identificaron tres direcciones diferentes: "Breslau", "Berlin W. Kurfürstendamm 101" (ambas en bases de color marrón claro) y "Grünewald, Berlin- Bismarckallee 53" (en bases de color negro). En un catálogo de Brendel de 1885 se detalla "Kurfüstendamm 101" como dirección de la fábrica en Berlín, por lo que una parte de la colección resultaría ser cercana a esta fecha. La referencia a la ciudad es otro de

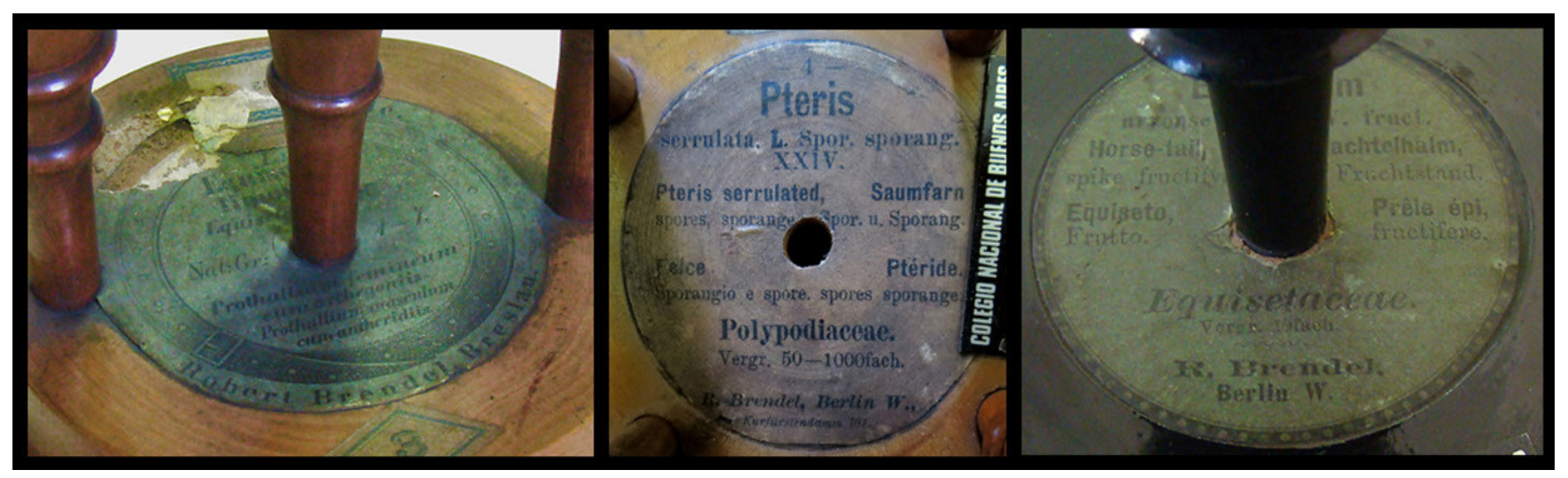

Figura 3.- Diferentes tipos de etiquetas de la firma Brendel adheridas en las bases de madera de los modelos. Colección CNBA. 
los datos que puede ayudar a deducir la antigüedad de los objetos. [Figura 3].

Por otra parte, en el Colegio Nacional de Buenos Aires se conserva un inventario antiguo del entonces Laboratorio de Historia Natural iniciado en Febrero de 1903. En él se registró la existencia en esa fecha de 70 ejemplares y en una nota de abril de 1903 se registró la incorporación de otros 67 modelos botánicos, sumando un total de 137 modelos. Este tipo de documentos resulta uno de los más importantes para conocer los períodos de adquisición de material didáctico en la institución y también identificar las pérdidas que pudieran haberse suscitado. Por otros registros encontrados, se dedujo que la colección llegó a 160 ejemplares hacia $1930^{12}$, pero actualmente conserva sólo 66, siendo menos de la mitad. A lo largo de los años y a medida de que estos modelos se deterioraban, rompían o dejaban de ser útiles para la enseñanza, eran desestimados y desechados. Otros ejemplares contrariamente, continúan en uso. Las flores de Brendel, por ejemplo, son empleadas en los trabajos prácticos del curso de Biología de Tercer año. Algunos docentes aún hacen énfasis en la calidad de las representaciones y la eficacia de las didácticas promovidas por estos objetos. En este sentido, la recuperación de estos modelos también contempló los usos actuales de la colección.

\section{Estudio, conservación y restauración de la colección Brendel}

El proyecto de conservación y restauración de los modelos Brendel fue posible gracias al aval institucional y al apoyo económico de la asociación cooperadora de padres ${ }^{13}$ y en ese marco se realizaron los trabajos de documentación, análisis técnico y de laboratorio, conservación y restauración. En una primera etapa, durante el año 2007, se identificaron el modo de presentación de los modelos, los materiales originales y las técnicas. Se comenzó por un análisis morfológico y organoléptico para el estudio de las formas del objeto, el sustrato y el acabado superficial. Este primer acercamiento permitió comenzar con la validación de las hipótesis sobre materiales y técnicas de la colección y entablar los criterios de intervención.

Los modelos Brendel están básicamente organizados en dos secciones: la base y el cuerpo principal o representación: en la base -de madera torneada, en color marrón claro o color negro- se encuentra la etiqueta, circular o rectangular, con información del modelo y del espécimen representado. Algunos ejemplares, también conservan una chapa metálica plateada en alto relieve con la ciudad y dirección de la empresa. Las bases por su parte, tienen incorporadas elementos de encastre en madera torneada que sirven de unión con el cuerpo principal y varían en número según la cantidad de piezas que posee el modelo. Esta sección está compuesta por las representaciones de los especímenes que llevan insertas unas varillas cilíndricas como soporte. Estas varillas elevan al modelo a una determinada altura desde su base.

A través de los ejemplares conservados en el Colegio Nacional de Buenos Aires se determinó que algunos modelos son desarmables y otros fijos, pueden presentarse en una sola pieza o en varias y en diferentes escalas. Por otro lado, la colección muestra diversidad de materiales y técnicas utilizadas. La firma además del papel maché, fabricó modelos enteramente en otros materiales como resina vegetal y gelatina, o combinados, con el fin de lograr representaciones fidedignas en formas y texturas. En la colección del Colegio Nacional se conservaron en su mayoría modelos fijos (48 ejemplares), solo 17 modelos de los 66, poseen piezas móviles y/o desarmables. En relación a las técnicas y materiales, del total, se identificaron 29 modelos realizados principalmente en papel maché, 18 en resina y 9 en gelatina. Varios combinan más de dos o tres materiales, reconocibles en los diferentes elementos, habiendo 10 donde no es posible identificar un material predominante.

La utilización del papel maché, se observa principalmente en pétalos, hojas, vainas y anteras. La mayoría de las formas realizadas en este material posee una estructura interna metálica de alambre, a modo de nervaduras, para mantener las formas abiertas como en el caso de los modelos de flores. Por otra parte, un material opaco y negro conforma el sustrato de algunas piezas, reconocida al principio como una resina de tipo natural. La gelatina, podemos encontrarla en la representación de membranas o estructuras celulares. Otros materiales como el yeso y la madera aparecen combinados según las necesidades de la representación como por ejemplo anteras y pistilos respectivamente.

En cuanto al acabado superficial, la técnica es una pintura al aceite con una base de preparación blanca. Sobre la superficie de los modelos otros materiales fueron utilizados para la imitación de texturas tales como, plumas, cerdas y fibras naturales, cabello y algodón, entre otros.

\section{-Estudios puntuales de identificación de materiales}

Tras efectuar estos primeros acercamientos, se profundizó en el conocimiento de los materiales a través de análisis de laboratorio para una identificación más precisa. Con la colaboración del Instituto Nacional de Tecnología Industrial (INTI) se realizaron estudios analíticos y observaciones a microscopio. Esta parte de la investigación se logró gracias a la ayuda de investigadores del Centro de Celulosa y Papel y del Centro de Procesos Superficiales dependientes del $\mathrm{INTI}^{14}$. Para estos estudios se eligieron modelos completos que combinaran diferentes materiales y de donde pudieran extraerse muestras representativas de la colección. Al INTI se trasladaron los modelos elegidos para la selección de las muestras en conjunto con los investigadores de la misma. El criterio para decidir qué estudios realizar estuvo 
determinado por la necesidad de disipar dudas puntuales sobre ciertos materiales y corroborar las conclusiones sacadas en el período de observación organoléptica.

En primera instancia, se utilizó la lupa estereoscópica y el microscopio óptico para la observación y mejor visualización de los materiales tales como el sustrato papel y la estructura de las varillas utilizadas como soporte. Esta exploración mostró que el papel maché fue confeccionado por capas adheridas entre sí y para la identificación de las fibras, se realizó un proceso de separación por inmersión en agua y agitación de una escama de papel desprendida. Dada la cantidad de adhesivo, el proceso resultó complejo, pero se pudo especificar que se trata de material de origen leñoso, siendo un papel obtenido de una pasta de madera. Esto corroboró lo observado anteriormente y aportó información sobre el tipo de papel utilizado, información que dio fundamento a las intervenciones realizadas en la restauración como fue la reconstrucción de formas faltantes.

Por otra parte, en el estudio de las varillas insertas en los modelos, se determinó que es un producto artificial e industrial, fabricado con fibras de celulosa amalgamadas, identificadas a través de un proceso de tinción como fibras de álamo. En un principio se tenía la hipótesis de que se había utilizado madera natural trabajada de determinada manera para lograr los diferentes espesores y formas en las varillas. En este sentido, conocer que era un material reconstituido dio una justificación más aceptable a lo observado en cuanto a la gran variedad de tamaños y curvaturas de varillas que posee la colección. Se observó además que estambres y pistilos fueron fabricados con este mismo material. [Figura 4]

En una segunda instancia, se realizó la identificación de los elementos utilizados en algunos detalles y texturas, eligiendo como muestras representativas, fibras pertenecientes a diferentes modelos. En estos estudios se identificó el uso de la fibra de seda en la mayoría de los casos donde se imitó a las fibras vegetales de las plantas, como por ejemplo, en la superficie de anteras y sépalos. Otros casos particulares se estudiaron, como por ejemplo, un detalle realizado en un modelo de flor y otro en un modelo de una planta de cereal. En el primero se observó una estructura entrelazada de fibras de seda y en el otro caso se identificó la utilización de pluma. Estos detalles pueden ser visualmente similares pero en su naturaleza muy diferentes. [Figura 5]

Por otra parte, se tomaron diversas muestras de capa pictórica con el fin de conocer en rasgos generales su estructura y composición y corroborar las hipótesis en cuanto a su naturaleza oleoza. Para esto, se utilizó la Espectroscopia infrarroja por transformada de Fourier (FTIR), que confirmó el uso de aceite como médium. Además, se
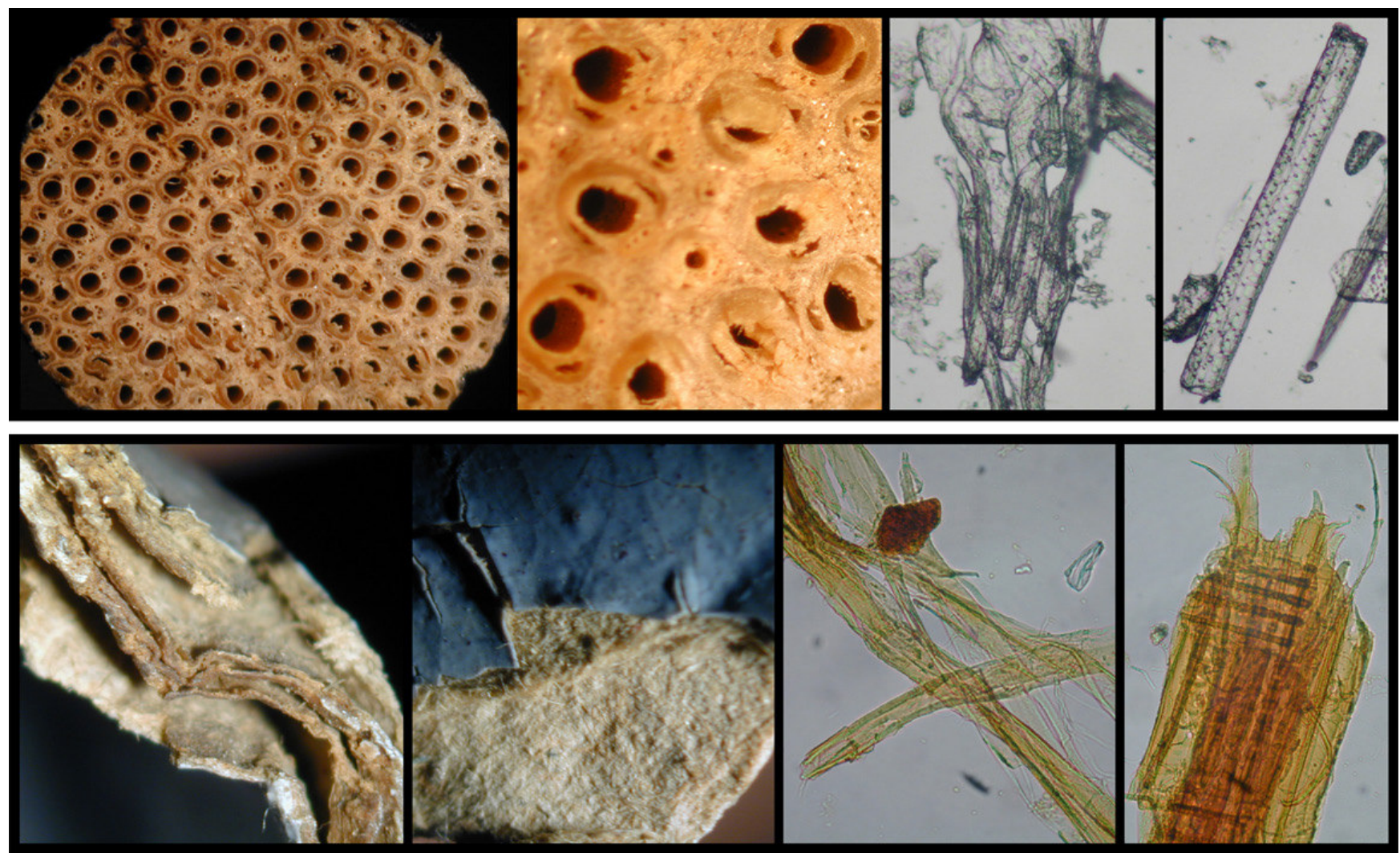

Figura 4.- Varillas de soporte (superior) e identificación del sustrato papel (inferior). Muestras obtenidas de los modelos C22 Secale cereale (espiga) y C28 Iris germánica (flor) respectivamente. Colección CNBA. Estudios obtenidos del Instituto Nacional de Tecnología Industrial (INTI) 




Figura 5.- Identificación de fibras utilizadas como texturas: Detalles del modelo C28 Iris germánica (flor) -antera y estructura entrelazada de fibras- identificados como fibras de seda (izquierda) y del modelo C22 Secale cereale (espiga) identificada como pluma (derecha). Colección CNBA. Estudios obtenidos del Instituto Nacional de Tecnología Industrial (INTI)

empleó el Microscopio electrónico de barrido y microanálisis elemental mediante energía dispersiva de rayos $X$ (SEMEDAX) para un análisis estratigráfico y elemental, realizado en esta ocasión en los establecimientos del SEGEMAR (Servicio Geológico Minero Argentino).

El resultado de este análisis dio a conocer que la capa pictórica, en la mayoría de las muestras estudiadas, se compone básicamente de una primera capa de imprimación liviana, a modo de sellado de las fibras del papel sobre la que se le aplicó un estrato de pintura blanca de mayor espesor para finalizar con una capa pictórica de color. Este estudio confirmó la hipótesis de la utilización de una base blanca previa a la de color y que se trata en general de una capa pictórica delgada. Esta característica fue tomada en cuenta en las intervenciones de limpieza y consolidación de la superficie pictórica ya que algunos modelos presentaban deterioros tales como pulverulencia de la pintura, abrasión, fisuras, escamas y pérdidas. En las muestras estratigráficas no se pudo determinar con certeza la existencia o no de una capa de protección o de barniz, aunque visualmente pudiera parecer que la misma existía. La composición química-elemental de la capa pictórica resultó ser la siguiente: Capa 1: imprimación: $\mathrm{CaCO}_{3}$ (carbonato de calcio); capa 2: base blanca: $\mathrm{Zn}$ puro, espesor: $2 \mathrm{~mm}$. y capa 3: pintura de color claro: alto contenido de $\mathrm{Zn}$ y $\mathrm{Pb}$. [Figura 6 y 7 ]

Por último, se analizaron muestras de la gelatina y la resina utilizadas como sustrato en algunos ejemplares. El estudio se realizó también mediante Espectroscopia infrarroja por transformada de Fourier (FTIR). Los espectros obtenidos de los modelos Brendel, ratificaron la naturaleza proteica de la gelatina y permitieron conocer la resina utilizada como de origen vegetal, al presentar las bandas características de una resina de este tipo. Esta información permitió idear los procedimientos del taller, por ejemplo, para producir un material de gelatina que tuviera propiedades similares al del modelo original y que pudiera ser utilizado en la consolidación y reintegración material de los modelos con faltantes. [Figura 8]

\section{-Conservación y restauración}

En la etapa de la restauración, se intentó construir el mejor criterio, recurriendo a todo recurso útil para el conocimiento de los objetos: investigación histórica universal y local, asesoramiento con diferentes profesionales, corroboración científica a través de exámenes analíticos de los materiales constitutivos, intercambio de conocimientos con otras instituciones y consultas con curadores y restauradores extranjeros ya experimentados en la preservación de este tipo de patrimonio. Por otra parte, con esta información se procuró devolver la funcionalidad didáctica a los objetos ya que estos eran aún requeridos en las prácticas del aula. En este sentido, los debates en torno a la reconstrucción o no de los faltantes, por ejemplo, se basó prácticamente en la posibilidad de llevarlas a cabo según la información que hubiese podido recabarse de otras representaciones en colecciones paralelas y si tal reposición era relevante o no en su función didáctica actual. En todos los casos fue constante el trabajo interdisciplinario con el plantel docente del CNBA. 

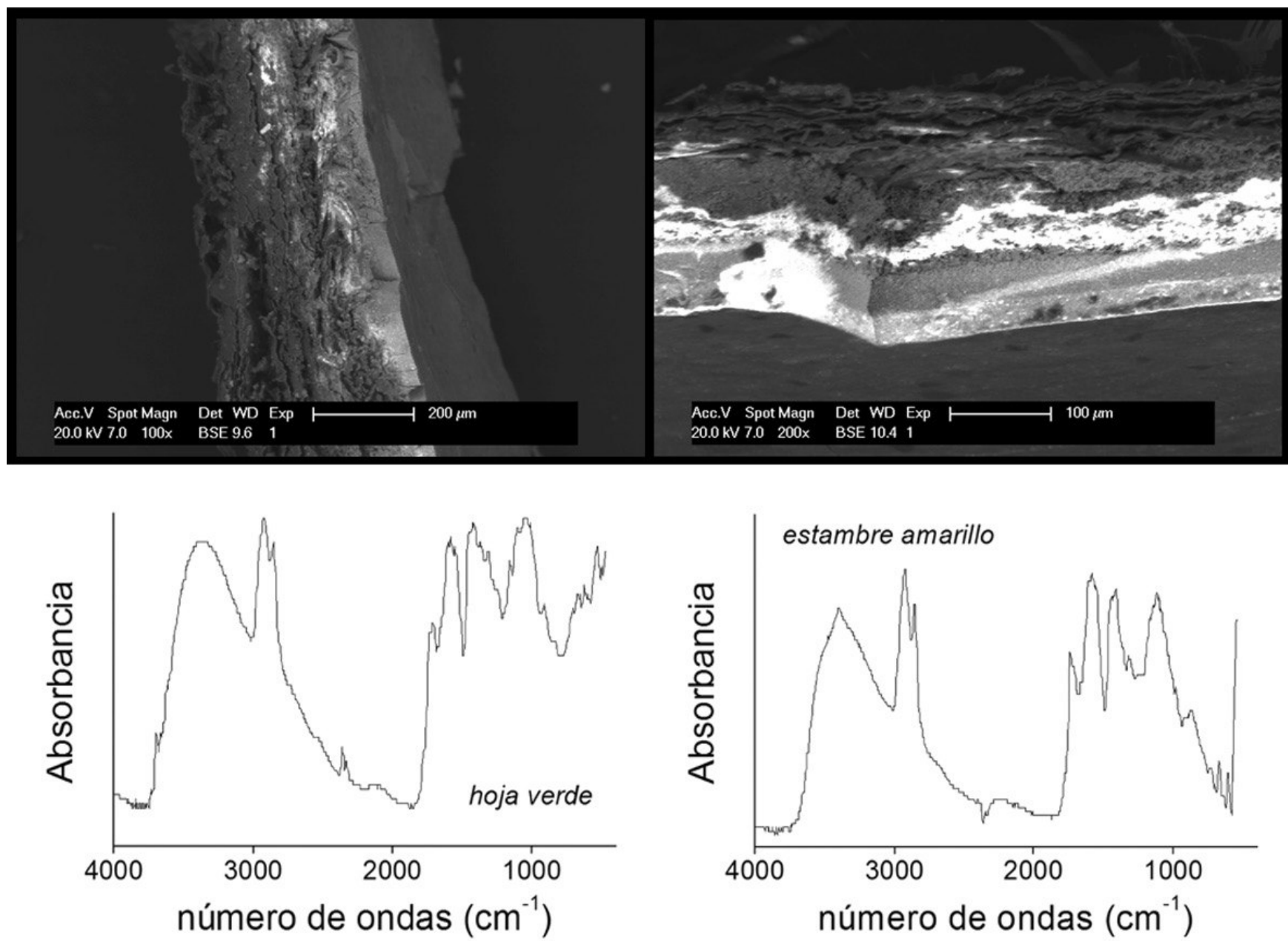

Figura 6.- Estudio de la capa pictórica: estratigrafías (sección transversal) y análisis FTIR - Muestras seleccionadas de los modelos C22 Secale sereale (espiga) y C27 Butomus umbelatus (flor). Colección CNBA. Estudios obtenidos del Instituto Nacional de Tecnología Industrial (INTI).

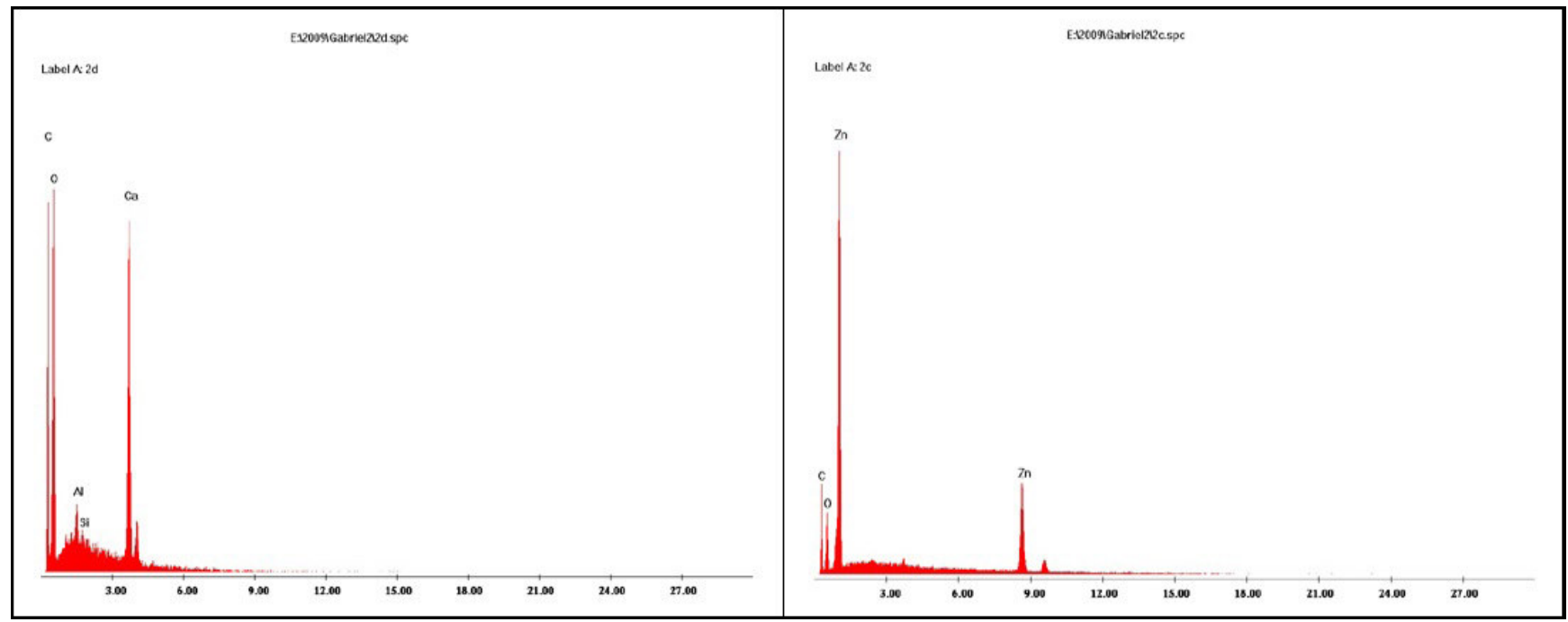

Figura 7.- Análisis elemental SEM-EDAX. Ejemplos de los espectros obtenidos mediante este estudio, en este caso: imprimación y primera capa de pintura -base blanca-. Estudios obtenidos del Instituto Nacional de Tecnología Industrial (INTI) 

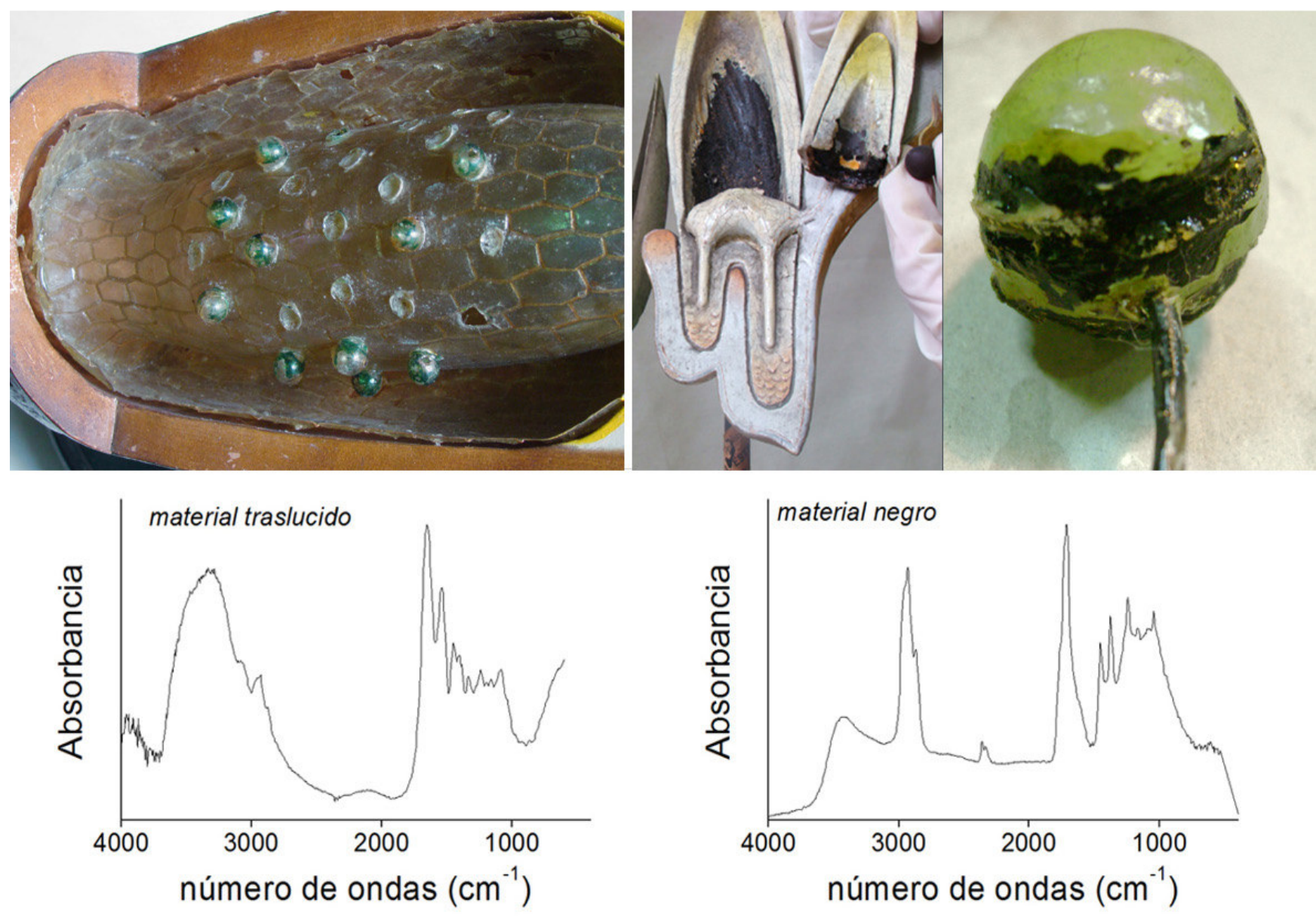

Figura 8.- Identificación por FTIR del material gelatina y la resina color negro. Detalles de los modelos E63 Brachytecium rutabulam gelatina, C23 Secale cereale (germinación) y A02 Equisetum limosum (espora) -resina. Colección CNBA. Espectros obtenidos del Instituto Nacional de Tecnología Industrial (INTI).

El período de observación detallada de la colección, la recopilación de información y la investigación realizada junto con el INTI, fueron las herramientas con las que se contó para seleccionar la metodología técnica más propicia en la intervención de cada objeto. Por un lado se comenzó la intervención desde el punto de vista de una restauración de pintura al óleo, planteando los criterios de intervención convencionales empleados en este tipo de pinturas. En este caso, la variable más importante resultaba ser el sustrato ya que era diferente entre los modelos y podía llegarlo a ser también entre las partes de un mismo modelo.

Los deterioros observados en los objetos fueron de gran ayuda para el reconocimiento de los diferentes sustratos. En rasgos generales, la mayor causa de los deterioros presentes en los materiales fue debido a su uso: se observaron deterioros de nivel físico en mayor medida como roturas y quiebres, desprendimientos y deformaciones y en menor medida de nivel químico, como es la acidificación de los materiales, oxidación, pérdida de adhesión, perdida de aglutinantes, entre otros. Se observaron pocos problemas en relación a cuestiones medioambientales, lo que indicó cierta estabilidad del espacio donde se guardaban los objetos.
Como se mencionó anteriormente, varios de estos objetos siguen utilizándose en las aulas, lo que constituyó un factor a tener en cuenta a la hora de medir el alcance de las intervenciones en cada caso. Teniendo en cuenta las inquietudes y necesidades trasmitidas por los docentes, se decidió que restablecer la función didáctica de cada modelo se realizaría a través de una devolución completa de la lectura visual del espécimen representado. En este sentido, se puso mayor énfasis en el aspecto visual, determinando una intervención de tipo imitativa en las instancias de reintegración de formas y de color.

Por otra parte, se intentó en la restauración contrarrestar algunos procesos de degradación de los materiales para lograr mayor fortaleza en zonas de unión y encastres. Por ejemplo, para la reposición y consolidación del sustrato papel, que se encontraba en muchos casos quebradizo y con pérdida de adhesión entre capas, se utilizó papel japonés -de fibras largas y de algodón (sin lignina)- en diferentes gramajes y con adhesivos naturales como el almidón y otros sintéticos, como la metil-celulosa, para aplicarlo entre las capas del papel original o como relleno de faltantes, imitando las técnicas originales de construcción. 
La devolución de la lectura de los objetos requirió en muchos casos reponer formas completas o faltantes de gran tamaño. Para esto se valió de las dos técnicas de papel maché según conveniencia: el papel maché en capas y el papel maché a base de pulpa de papel. En la fabricación de "copias" de estructuras delgadas como pétalos y algunas estructuras huecas se utilizó el papel en tiras adherido entre sí y tomando las formas originales de referencia como moldes ${ }^{15}$. Para esta técnica se utilizó adhesivo de almidón. En otros casos se utilizó el modelado del papel triturado o pulpa para la reconstrucción de anteras y estructuras de mayor tamaño. Como estos elementos requerían mayor dureza, a la pasta de papel se le agregaba adhesivo vinílico (PVA) neutro libre de ácido como aglutinante y carbonato de calcio como carga inerte. Por otra parte, la reintegración cromática se realizó con acuarela para garantizar su reversibilidad en caso de que fuera necesario. Posteriormente se protegieron las zonas de reintegración pictórica con un barniz reversible a base de resina cetónica, soluble en solventes de baja polaridad. [Figura 9]

En la colección Brendel los desafíos de la restauración estuvieron también en torno a la intervención de los otros materiales utilizados en la construcción de los objetos como fue el caso de la gelatina. Los modelos realizados en este material presentaban quiebres y faltantes, no tanto así grandes deformaciones. Para conocer más sobre las propiedades y posibilidades técnicas de una gelatina (proteína-colágeno), se realizaron pruebas dentro del taller. En primera instancia, las necesidades de restauración estaban asociadas a la consolidación y la reintegración de faltantes en las piezas, por lo que el material debía ajustarse a ciertos requisitos de adhesividad, elasticidad y transparencia. Se indagó entonces, sobre las posibilidades técnicas de producción de láminas traslúcidas y flexibles que permitieran no sólo la reconstrucción y consolidación de las formas deterioradas del modelo, sino también las posibilidades de adaptación morfológica y resistencia a los cambios medioambientales una vez unidas y adheridas.

Se realizaron diversos ensayos con gelatina de origen animal -cola de conejo- en diferentes concentraciones y con aditivos como melaza y conservantes. Los resultados mostraron que las láminas realizadas con mayor grado de dilución poseían mayor flexibilidad al deshidratarse ${ }^{16}$. Sobre esta premisa se fabricaron artesanalmente láminas de diferentes espesores, con diferentes niveles de transparencia y tonalidad que el original imponía, ya que para una lectura estética más homogénea, no sólo había que imitar el material sino también su apariencia. En este sentido, la utilización de acuarela resultó útil para dar color a la gelatina y a la vez disminuir su transparencia, no así en cambio las tintas chinas, con las que se experimentó, que aportaban tonalidad pero no modificaban el grado de transparencia. Una vez adheridas las reposiciones con la misma cola animal, se decidió aplicar sobre las reintegraciones de gelatina, una delgada capa de barniz acrílico Paraloid ${ }^{\circledR}$ B72 (5\% en tolueno) como protección. Esta resina se aplicó a pincel cuidando no impregnar el material original y con el fin

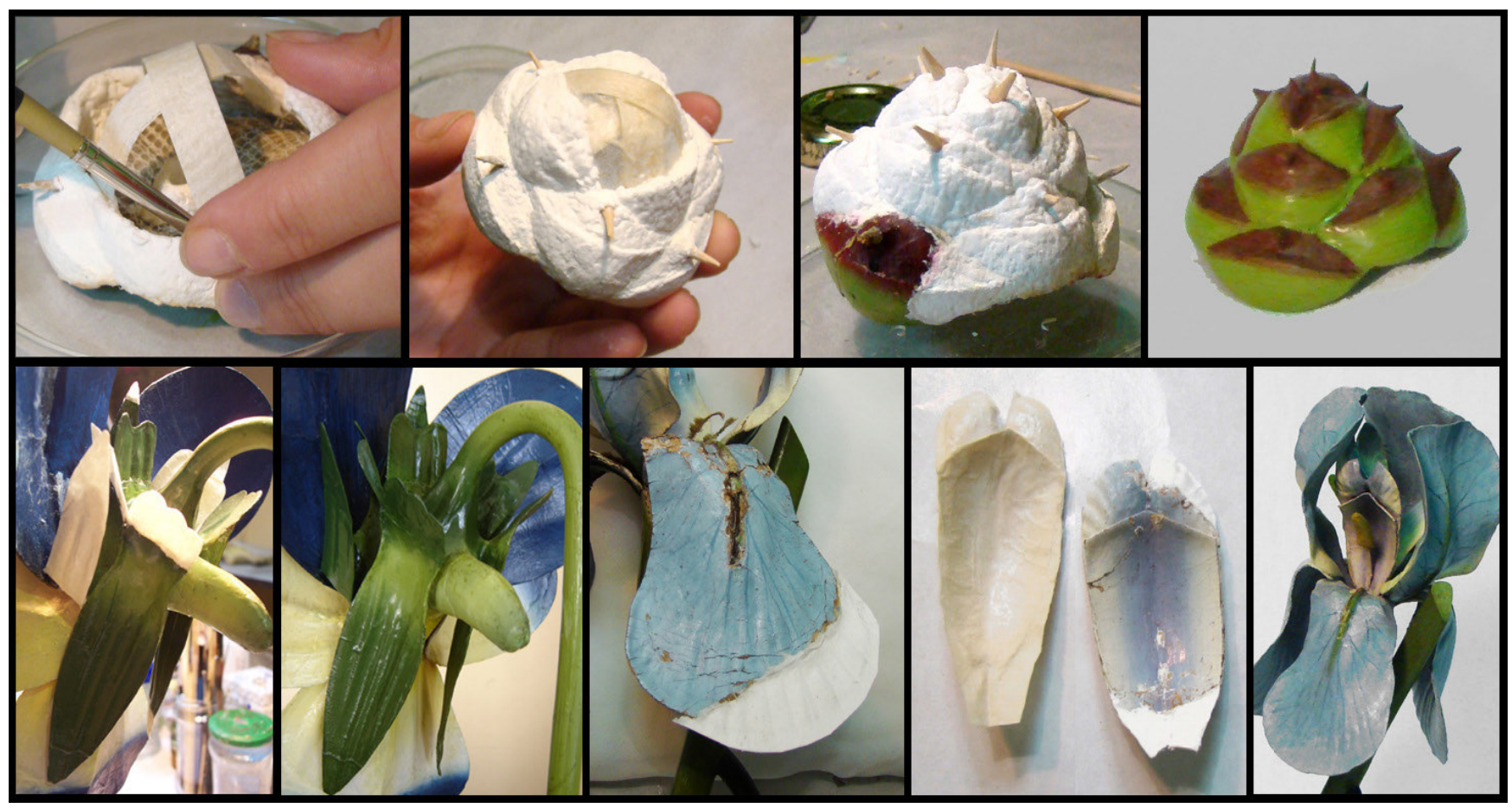

Figura 9- Reposición de formas. Detalles de la restauración realizada en los modelos B16 Pinus silvestris (cono femenino), D41 Viola tricolor (flor) y C28 Iris germánica (flor) respectivamente. Colección CNBA. 


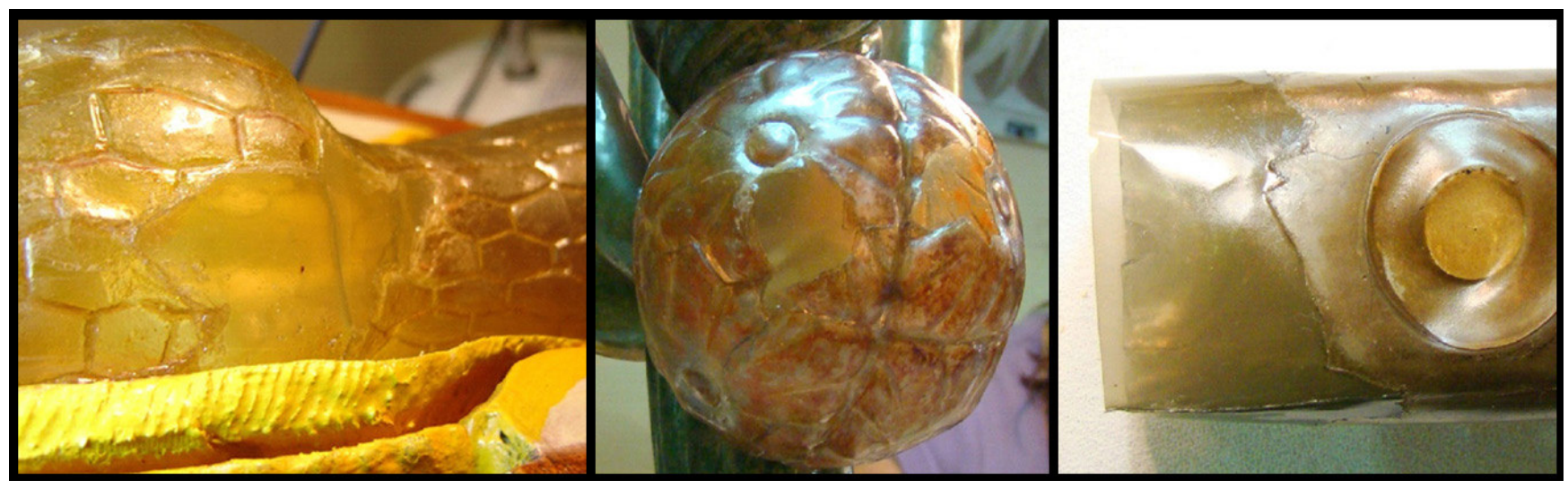

Figura 10- Reintegraciones realizadas en modelos de gelatina. Detalles de los modelos E63 Brachytecium rutabulum; E64 Chara fragilis y B20 Traqueida, respectivamente. Colección CNBA.

de disminuir las posibilidades de futuras deformaciones por higroscopicidad de la gelatina repuesta. Observando estas intervenciones en el tiempo, los resultados fueron positivos, ya que al día de hoy, los modelos restaurados no presentan deformaciones ni fisuras por estrés o modificaciones en los materiales, indicando una aceptable compatibilidad entre la gelatina original y la gelatina repuesta. [Figura 10]

\section{Conclusión}

Las diferentes metodologías utilizadas de investigación permitieron obtener conocimientos útiles para el desarrollo de los trabajos de conservación y restauración en esta colección, como así también, para dar a conocer a la comunidad en general los diferentes aspectos vinculados a este tipo de objetos. A través de este trabajo se intentó mostrar los datos que pudieron recabarse y las técnicas que se desarrollaron en el marco del proyecto y que hicieron posible su puesta en valor. Asimismo, uno de los objetivos fue remarcar algunas particularidades convenientes a tener en cuenta al momento de trabajar con este tipo de objetos y en especial los modelos Brendel. Al momento de encarar trabajos de conservación y restauración en colecciones de este origen, se debe recordar que no sólo puede encontrarse la técnica del papel maché, una técnica sencilla de entender en rasgos generales, sino también un conjunto de otros materiales de diversa naturaleza utilizada y combinada de muchas manera dentro de un mismo modelo y dentro de una misma colección. El modo de empleo de los materiales y las técnicas difieren de las utilizadas en otros modelos del mismo tipo y de la misma época, como los del mencionado francés Auzoux, que prácticamente no varía su técnica de construcción en casi cien años de producción.

Las indagaciones aquí presentadas son igualmente básicas ya que otros interrogantes quedan todavía por resolver tales como las diferencias en la construcción de los modelos a lo largo del tiempo y la identificación de otros componentes en los materiales utilizados. Se ha observado que los materiales y las formas presentes en la colección varían entre los modelos datados en una fecha más cercana a los orígenes de la empresa y los fabricados a principios del siglo XX. Es posible que a lo largo del período de fabricación de la firma se hallan producido tres o cuatros maneras diferentes de representar un mismo espécimen.

Para llevar adelante la instancia de restauración fue fundamental entender esta lógica y en consecuencia decidir las técnicas de intervención en cada caso. Por otra parte, se requirió de la experimentación en el marco del taller y el aporte de datos obtenidos por análisis de laboratorio para poder resolver los desafíos que implicó cada material existente en los objetos. Afortunadamente las intervenciones no solo devolvieron una lectura visual unificada a los objetos, sino también que reflejaron estabilidad estructural a lo largo del tiempo. Hasta el día de hoy la colección Brendel se encuentra disponible para su uso en las aulas y también para su exhibición y conocimiento por parte de la comunidad en general, pudiendo cumplir con los objetivos fundamentales de la preservación de estos bienes culturales.

\section{Agradecimientos}

Se agradece principalmente a la Dra. Susana V. García, por el asesoramiento histórico y la lectura crítica del manuscrito y a Oscar Monkes, por la revisión de este artículo y la colaboración en el desarrollo del proyecto. A mis colegas del Grupo de Conservación, a la comunidad del Colegio Nacional de Buenos Aires y a los profesionales del INTI, que hicieron posible la realización de este proyecto. A los diferentes profesionales que han colaborado con información y documentación relacionada a la colección Brendel como Henri Reiling y Paul Lambert de la Universidad de Utrecht, José María Pizarro de la Universidad Complutense de Madrid y 
Fernando Gabriel Ranea de la Universidad de Buenos Aires. Y a los docentes e investigadores que integraron el Programa I+D CEIMES (CCHS-CSIC y UNED) en España, que colaboraron al momento de mi estadía en dicho país, con el acceso a otras colecciones para observaciones comparativas.

\section{Notas}

[1] Página web del museo: http://www.cnba.uba.ar/mheq/

[2] Integrado por Amalia De Grazia, Ana Wortley, Eugenia Guidobono y María Gabriela Mayoni.

[3] Existen numerosos estudios sobre los modelos Auzoux en torno a su historia, producción y técnicas de realización. Entre ellos se pueden mencionar, los realizados por los investigadores de las colecciones del Museo de Alfort en Francia (Degueurce 2012; Dumont et. al. 2011; Charles Ruiz 2010), de la Universidad Complutense de Madrid en España (García Fernández et. al. 2009) y del Museum Boerhaave en Holanda (Nijhoff et. al. 2008; Grob, 2000).

[4] Las primeras publicaciones sobre la colección Brendel encontradas fueron la del investigador Henri Reiling de la Universidad de Utrecht publicado en el año 2003 y los informes sobre la conservación de modelos Brendel en el Museo de Liverpool del Conservador Tracey Seddon en el año 1994.

[5] Proyecto de investigación doctoral "Colecciones, museos y enseñanza científica en la educación media argentina (18701920)". CONICET-Archivo Histórico del Museo de La Plata, FCNyM, Universidad de La Plata. 2013-2018. Directora: Susana V. García.

[6] Un modelo Auzoux a escala real de un hombre o de un caballo, por ejemplo, podía llegar a un centenar de piezas constituyentes desarmables y miles de elementos anatómicos representados.

[7] Ver Seddon 1994; sitio web: http://www.liverpoolmuseums. org.uk/wml/collections/botany/images-models.aspx [consulta: Septiembre 2015].

[8] Información obtenida de José María Pizarro Domínguez, Conservador Herbario MAF. Universidad Complutense de Madrid. https://www.ucm.es/c.modelos.botanica [consulta: Septiembre 2015].

[9] Ver Fiorini et. al 2008.

[10] Información obtenida del Conservador Paul Lambers de la Universidad de Utrecht.

[11] Se han tomado como referencia los catálogos de la empresa Brendel a los que se ha podido tener acceso: 1885, 1893 y 1913/1914 (vigente hasta 1922) y los catálogos de empresas que comercializaban estos modelos encontrados en el Colegio Nacional de Buenos Aires como el de F. Volckmar de Leipzig de 1910 y el de Gallenkamp \& co. de Londres de principios de siglo $\mathrm{XX}$.

[12] En unas fichas bibliográficas encontradas de 1926, fue registrada la colección con datos taxonómicos y detalles de los modelos; están manuscritas en tinta y se las ha adjudicado al profesor Enrique Peralta Ramos, quien entre 1926 y 1943 se desempeñó como Jefe del Gabinete de Botánica. Las fichas encontradas tienen un número escrito que coincide con una inscripción en la cara inferior de las bases de los modelos Brendel, deduciendo a través de ellas el número de ejemplares que la institución llegó a tener en esa época.

[13] La Asociación Cooperadora "Amadeo Jacques" del Colegio Nacional de Buenos Aires, desde su creación en la década de 1960, ha tenido un papel importante en el desarrollo educativo de la institución promoviendo mejoras en la calidad educativa y brindando apoyo considerable para el mantenimiento y preservación edilicia.

[14] Se agradece especialmente al Ingeniero Marcelo Novaresi del Centro de Celulosa y Papel y al Dr. Gabriel Ybarra del Centro de Procesos Superficiales, quienes accedieron a colaborar con los estudios científicos sobre los materiales de esta colección como aporte al trabajo de tesis de grado "Puesta en valor de Bienes Culturales en el Colegio Nacional de Buenos Aires. Colecciones Didácticas de Modelos Anatómicos en Papel Maché del S. XIX" de la Universidad Nacional de las Artes, ex IUNA, dirigida por Oscar Monkes, actual conservador del Museo de Arte Moderno de la Ciudad de Buenos Aires.

[15] Este proceso de copiado se realizó procurando un interfoliado con papel aluminio entre la forma original y el papel humedecido, para evitar el contacto entre sí.

[16] La fórmula que resultó más exitosa en la experimentación fue la dilución de la cola animal a un $25 \%$ en agua destilada. Esta dilución se ubicaba sobre una bandeja de tereftalato de polietileno (PET) grueso hasta un espesor de $3 \mathrm{~mm}$. en húmedo y se dejaba deshidratar a temperatura ambiente. En cuanto a los aditivos, se le agregaba a la dilución $2,5 \mathrm{ml}$. de miel y 2 gotas de fenol por cada $50 \mathrm{ml}$. de dilución.

\section{Bibliografía}

AUZOUX, L. (1858). Leçons Élémentaires d'Anatomie et de Physiologie Humaine te Compareé. 2da. Edición. París: Labe Editeur, Libraire de la Faculté de Médicine.

BRENDEL, R. (1913-1914). Preisliste der botanischen Modelle. Berlin: Hermann Klokow.

CHARLES RUIZ, G. (2010). Les modeles en papier mache du docteur Auzoux au Musee de L'Ecole Nationale Veterninaire d'Alfort . [Tesis doctoral] Francia: Ecole Nationale Veterninaire d'Alfort. 
COCKS, M. M. (2014). "Dr. Louis Auzoux and his collection of papier-mâché flowers, fruits and seeds", Journal of the History of Collections, 26-2: 229-248. Oxford.

DASTON, L. J. (2008). "The Glass Flowers". En Things That Talk. Object Lesson from Art and Science, Daston, L. (coord), New York: Zone books, 223-254.

DEGUEURCE, C. (2012). Corps de papier. L'anatomie en papier mâché du Docteur Auzoux. París: Éditions de La Martiniére.

DUMONT, B., DUPONT, A-L., PAPILLON, M-C, et. al. (2011). "Technical Study and Conservation Treatment of a Horse Model by Dr. Auzoux", Studies in Conservation, 56: 58-74, UK: IIC.

FIORINI, G.; MAEKAWA, L.; STIBERC, P. (2008). "Save the Plants: Conservation of Brendel Anatomical Botany Models", The Book and Paper Group Annual 27, 35: 36-45.

FOURNIER, E. (1866). “M. Robert Brendel, Riemerzeile, no 15, Breslau, offre des modèles de fleurs [etc.]", Bulletin de la Societé Botanique de France, 13-2: 96. París: Martinet.

GARCÍA, S. y MAYONI, M. G. (2013). "Las colecciones de enseñanza científica como fuentes para la Historia de la ciencia.", Revista Electrónica de Fuentes y Archivos, 4: 110-125. Córdoba: Centro de Estudios Históricos "Prof. Carlos S. A. Segreti".

GARCÍA ADÁN, P. (2014). "El papel maché y la forma tridimensional". En Modelos y maquetas: la vida a escala. Madrid: Ministerio de Educación, Cultura y Deporte de España. 160-169.

GARCÍA FERNÁNDEZ, I.; GARCÍA FERNÁNDEZ, S.; SAN ANDRÉS MOYA, et. al. (2009). “Función, uso y exposición: el caso de los modelos anatómicos del Dr. Auzoux". En La Restauración en el siglo XXI. Función, Estética e Imagen. Cáceres: Grupo Español del IIC. 341-348.

GONZÁLEZ GASS, V. (2010). "Programa de Preservación y Revalorización de Bienes Culturales". En Informe de Gestión CNBA 2007-2010. Buenos Aires, pp. 40-59. Disponible en: http:// gonzalezgass.com/wp-content/uploads/2011/05/Informede-Gestion-CNBA-2007-20101.pdf [consulta Septiembre 2015].

GROB, B. (2000). The World of Auzoux: Models of Man and Beast in Papier-Mâché, Leiden: Museum Boerhaave.

MAYONI, M. G. (2011). Puesta en Valor de Bienes Culturales en el Colegio Nacional de Buenos Aires. Colecciones Didácticas de Modelos Anatómicos en Papel Maché del S. XIX. [Tesis de grado]. Buenos Aires: Instituto Universitario Nacional del Arte (IUNA), Departamento de Artes Visuales "Prilidiano Pueyrredón".

MAYONI, M. G.; DE GRAZIA, A.; GUIDOBONO E.; WORTLEY, A. (2012). "La preservación del patrimonio educativo en el
Colegio Nacional de Buenos Aires", Ge-conservación, 3: 53-68, Madrid: Grupo Español de Conservación (IIC).

MOTEL, J-J. (2004). L'Anatomie Clastique et Le Musée de L'Écorché D'Anatomie du Neubourg. Neubourg, France.

NIJHOFF ASSER, E.; REISSLAND, B.; GROB, B., et. al. (2008). "Lost fingers, scurfy skin and corroding veins - conservation of anatomical papier-mâché models by Dr Auzoux", Preprints ICOM Committee for Conservation, 1 : 285-292.

OLRY, R. (2000). "Wax, Wooden, Ivory, Cardboard, Bronze, Fabric, Plaster, Rubber and Plastic Anatomical Models: Praiseworthy Precursors of Plastinated Specimens", J of Int Soc Plastination, 15-1: 30-35, International Society for Plastination

REILING, H. (2003). "Beter dan de natuur" [Better than Nature/ Besser als die Natur]. En NEO, Jan Brand \& Alex de Vries (eds.), Utrecht: Utrecht Central Museum. 221-235.

—(2009). “Über Blaschkas Glasmodelle und die zeitgenössische Naturgeschichte, mit einem Anhang über Brendels botanische Modelle" [On the Blaschkas' glass models and contemporary natural history, with an appendix on The Brendels' botanical models], En Michael Kaasch \& Joachim Kaasch (eds.): "Natur und Kultur" $y$ "Biologie im Spannungsfeld von Naturphilosophie und Darwinismus"; "Beiträge zur 15. und 16. Jahrestagung der DGGTB", Verhandlungen zur Geschichte und Theorie der Biologie, 14: 267-282. Berlin: VWB. http://members.ziggo.nl/here/ blaschka-brendel.html\#35 [consulta: septiembre 2015]

SANGUINETTI, H. J. (1963). Breve Historia del Colegio Nacional de Buenos Aires. Buenos Aires: Asociación Cooperadora "Amadeo Jacques".

SEDDON, T. (1994). "Conservation of Anatomical Botanical Plant Models". En Conservation and the Herbarium, R.E Child (ed), Tunbridge Wells: Institute of Paper Conservation, 29-33.

THORNTON, J. (1993). "The History, Technology, and Conservation of architectural papier mâché", Journal of the American Institute for Conservation, 32: 165-176.

VALDECASAS, A., CORREAS, A. M., RODRIGUEZ GUERRERO, C., et. al. (2009). "Understanding complex systems: lessons from Auzoux's and von Hagen's anatomical models", J. Biosci, 34-6: 835-843.

VAN DER REYDEN, D., WILLIAMS, D. (1986). "The Technology and Conservation Treatment of a 19th Century "Papier-Mâché" Chair", Preprints American Institute for Conservation. 14th Annual Meeting, Chicago, 125-142.

VOLCKMAR, F. (1910). Catálogo General de Material de Enseñanza y Útiles para Escuelas. Leipzig: Stephan Geibel \& Co. 


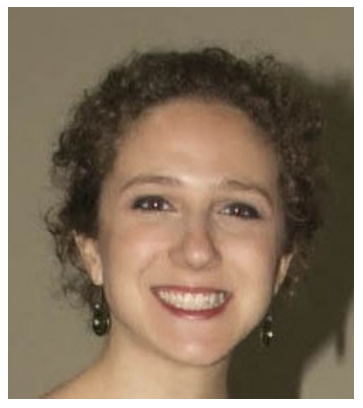

\section{María Gabriela Mayoni}

mgmayoni@gmail.com

Licenciada en Conservación y Restauración de Bienes Culturales por la Universidad Nacional de las Artes (UNA), Argentina. Es becaria CONICET y doctoranda en la Universidad de Buenos Aires con un trabajo de investigación sobre museos, colecciones y enseñanza científica en la educación media argentina durante las últimas décadas del siglo XIX. Dirigió y llevó a cabo junto a colegas el Programa de Preservación y Revalorización de Bienes Culturales en el Colegio Nacional de Buenos Aires para la puesta en valor de sus colecciones didácticas. Realizó estadías de formación en España, en el Museo Nacional de Artes Decorativas de Madrid como becaria y colaboró en ese país con varias instituciones y proyectos relacionados a la recuperación del patrimonio educativo. Realizó publicaciones en diferentes revistas electrónicas y expuso su trabajo en varios encuentros dentro y fuera de su país.

\section{Artículo enviado el 05/10/2015 \\ Artículo aceptado el 18/04/2016}

